\title{
A Study of the Impact on Soybean Potential under Climate Change
}

\author{
Qiuying Ding ${ }^{1}$, Zhan Tian ${ }^{1,2}$, Dongli Fan ${ }^{1}$, Laixiang Sun $^{2,3}$, Guenther Fischer ${ }^{4}$ \\ ${ }^{1}$ Shanghai institute of technology, Shanghai 21400, China \\ ${ }^{2}$ Shanghai climate center, Shanghai meteorological bureau, Shanghai 21400, 20030, China \\ ${ }^{3}$ Department of Geographic Sciences, University of Maryland, College Park 20742, USA \\ ${ }^{4}$ International Institute of Applied System Analysis, Laxenburg 2361, Austria
}

Received 31 July 2016

Accepted 25 March 2016

\begin{abstract}
Soybean is one of the important oil crops in China. However the supply and demand of soybean is at stake currently. The demand keeps increasing and the self-sufficient keeps decreasing. More seriously, climate change will bring obvious impact on the growth and development, planting pattern, planting area, potential production of soybean, etc. Therefore, assessment of the impact of soybean production under climate change is quite essential for improving the self-sufficient and guaranteeing the safety of oil crops. This study will extend and improve the parameters of soybean in agricultural ecology zone (AEZ) based on the 22 soybean observation stations in the major planting area from 1981-2011 to achieve China-AEZ. And then simulate the impact of climate change on soybean. The results show that: the simulation of China-AEZ has been improved a lot. In 2050s, the total soybean potential will increased by 7123 thousand tons. The total suitable planting area will increased by 3589 thousand hectare. But the average potential will decreased by $55 \mathrm{~kg} / \mathrm{ha}$. From the spatial scale, the soybean potential will increase in Northeast China and Northwest China. Soybean potential will decrease in the other area of China under climate change.
\end{abstract}

Keywords: Soybean, Climate change, AEZ, Production potential

\section{气候变化对我国大豆生产潜力的影响研究}

\author{
丁秋莹 ${ }^{1}$, 田展 ${ }^{1,2}$, 标冬丽 ${ }^{1}$, 孙来祥 ${ }^{2,3}$, Guenther Fischer $^{4}$ \\ 1 上海应用技术学院，上海 21400，中国 \\ 2 上海气象局上海市气候中心，上海 20030, 中国 \\ 3 马里兰大学帕克分校地理科学系, 大学公园市 20742 , 马里兰州, 美国 \\ 4 国际应用系统研究所, 拉克森堡 2361 , 奥地利
}

\begin{abstract}
摘 要: 大豆是我国主要的油料作物之一。然而, 目前我国大豆供给形势不容乐观。一方面需求增加, 自给 率较低; 另一方面, 气候变化将会影响我国大豆生长发育、种植模式、种植布局、生产潜力等, 因此客观 准确地评价气候变化对我国大豆生产的影响为提高我国大豆自给率、保障油料安全具有重大意义。本研究 基于 1981-2011 年我国大豆主产区的 22 个农业气象站点观测数据, 扩充并改进 AEZ(Agricultural Ecology Zone) 大豆的品种库参数, 利用 AEZ 模型模拟了未来气候变化对我国大豆生产潜力的影响。结果显示: 调整改进 后的 China-AEZ 模型对我国大豆主产区的区域模拟能力得到了较大的提高。总体来看，气候变化影响下，到 2050s 我国大豆总生产潜力将会比 1990s 增加 7123 千吨, 约为 4.15\%。大豆总适宜面积增加 3589 千公顷, 约为 $6.15 \%$ 。平均单产生产潜力减少 $55 \mathrm{~kg} / \mathrm{ha}$, 约为 $1.89 \%$ 。区域上来看, 气候变化将会引起东北以及西北 地区大豆生产潜力增加, 但其他区域均小幅减产。
\end{abstract}

关键词: 大豆; 气候变化; $\mathrm{AEZ}$; 生产潜力

添加: 国家自然基金（41371110，4167113 和 41601049）和中国气象局气候变化专项（CCSF2011330、 CCSF201110）资助。

通讯作者: 㚞冬丽, 女, 1976 年出生, 山西太原人, 讲师, 博士, 主要从事科学研究。通讯地址: 201418 , 上海市奉贤区海泉路 100 号, 上海应用技术学院, E-mail: fandongli2002@163.com。 
我国油脂资源短缺, 食用油供给形势严峻, 油 料长期存在着严重的供需矛盾。其中大豆是一种很 有价值的油料作物, 是重要的畜饲料, 生物燃料, 蛋白质等来源 ${ }^{[1]}$, 随着过去几十年间我国经济发展以 及人们生活水平的改善, 大豆需求量显著增加, 并 且预计这种增长趋势在未来还会持续 ${ }^{[2]}$ 。然而多年来 我国油料作物生产潜力徘徊不前, 大豆生产潜力也 连续走低 ${ }^{[3]}$ 。2003年开始, 我国进口大豆数量首次超 过国产大豆。未来气候变化将会严重影响我国大豆 生产, 进一步加大大豆生产的不稳定性, 供需矛盾 还将进一步加剧。因此明确气候变化对大豆生产的 影响, 对保障国家食用油供给安全具有实际的重要 意义。

过去短时期内全球气候发生了迅速变暖, 我国 年平均地表大气温度在过去 50 年内升高了 $1.1^{\circ} \mathrm{C}^{[4]}$, 这一增幅要高于全球地表平均温度变化。全国平均 降水总量变化不显著, 年代际波动较大, 降水趋于 集中, 全国平均暴雨和极端强降水事件的频率和强 度都有所增长 ${ }^{[5,6]}$ 。并且气候变暖会增加蒸散 ${ }^{[7]}$, 干 旱发生的频率和强度都会加强 ${ }^{[8]}$ 。此外, 随着全球变 暖, 异常偏冷性事件减少减轻; 而异常偏暖性极端 事件增多增强; 气候暖干化趋势会加重病害的发生 [9]。近年来极端气候事件发生的形式也更加多样性 [10]。气候变化势必会给农业生产带来严重影响。干 旱、极端天气等增加了农业生产的风险, 也将加大 大豆生产潜力的波动性。气候变暖影响下, 东北地 区作物生育期延长, 作物种植边界北扩, 能够促进 大豆的种植边界北移, 有利于扩大高纬度地区大豆 的种植面积 ${ }^{[11]}$ 。

从目前相关研究来看, 作物模拟模型是一种较 为系统综合的分析方法, 能够综合评估农业系统与 土壤、气候等因子之间的相互作用。随着科学技术 的发展进步和消费需求的增加, 作物模型无论在研 究深度还是应用广度上都取得了显著的成就。AEZ 模型是一种空间尺度的土地生产潜力评估模型, 该 模型在模拟作物生产潜力时, 采用的自动匹配算法 能够依据气候资源数据和LUT (土地利用单元) 属性 数据逐格点尝试所有可能性, 因此模型能够自动篮 选出最优的作物种植品种、种植模式等, 这使得AEZ 模型在区域作物潜在生产力评估中具有明显优势。
本研究基于我国多年大豆观测数据通过改进模型的 品种库参数以及算法, 建立适合我国大豆评估的 AEZ-China模型, 评估1990s（1981-2010）baseline条 件下与2050s(2041-2070)未来气候变化下大豆生产潜 力。

\section{1. 研究资料与方法}

\section{1. 研究资料}

土壤数据是从 HWSD (Harmonized World Soil Database) 土壤数据库中提取而来, 该数据库提供全 球范围内 $1 \mathrm{~km} \times 1 \mathrm{~km}$ 分辨率格网水平的土壤信息, 土壤数据分为顶层 $(0-30 \mathrm{~cm})$ 和下层 $(30-100 \mathrm{~cm})$, 土壤属性包括排水速率、土壤深度、容积密度、有 机碳有机质含量、土壤 $\mathrm{PH}$ 以及阳离子交换量等数据 信息, 可以供模型直接提取使用。

基准条件下的逐日气候观测数据来自国家气候 中心, 全国共设有 743 个气象站点, 主要的气象要 素包括逐日最低气温、最高气温、降水、日照时数、 相对湿度以及风速, 本研究选用 1981-2010 的气候数 据作为基准时段。未来气候变化数据是对未来温室 气体排放的不同情景进行的假设, 已有研究表明 IPCC AR4 气候模式结果对东亚和中国的气候变化具 有较好的模拟能力 ${ }^{[12]}$, 设计了多种排放情景, 对比 研究表明, 近年来温室气体增长率与 SRES A1B 情景 下的温室气体排放水平最为接近, 能够一定程度上 代表未来气候发展的方向, 因此本研究中采用 A1B 排放情景作为未来气候变化的趋势。

表 1 的大豆观测数据来自中国气象局信息中心 多年观测整理所得, 涵盖了全国主要大豆种植省份。 根据站点记录数据的完整性以及地理位置分布, 从 中国气象局提供的数据中挑选 22 个大豆站点, 数据 年份包括 1981-2011 年, 数据内容包括: 站点基本信 息（站点名称、经纬度、海拔高度）, 栽培信息（种 植品种、熟性、耕作方式等), 生长发育的详细信 息 (播种、出苗、开花、成熟等), 生产潜力及相 关信息 (种植密度、粒重、总生产潜力、茎秆重等) 以及主要的管理措施（施肥、灌溉、收获等）。该 表中的生产潜力是根据站点历年的纪录数据, 剔除 个别存在病虫草害的年份以及奇高的产量, 奇高生 
表 1. 大豆观测站点基本信息

\begin{tabular}{|c|c|c|c|c|c|}
\hline 省份 & 站点 & 经度 & 纬度 & 生产潜力 (kg/ha) & 生育期（天） \\
\hline 黑龙江 & 德都 & 127.35 & 46.08 & 4959 & 134 \\
\hline 黑龙江 & 巴彦 & 126.15 & 48.47 & 5448 & 137 \\
\hline 黑龙江 & 嫩江 & 125.23 & 49.17 & 4234 & 145 \\
\hline 辽宁 & 阜新 & 121.72 & 42.08 & 3243 & 134 \\
\hline 辽宁 & 盖州 & 122.35 & 40.42 & 4216 & 131 \\
\hline 辽宁 & 海城 & 122.72 & 40.88 & 4124 & 135 \\
\hline 吉林 & 辽源 & 125.08 & 42.92 & 4067 & 143 \\
\hline 内蒙古 & 扎兰屯 & 122.73 & 48.00 & 4946 & 135 \\
\hline 陕西 & 绥德 & 110.22 & 37.50 & 2499 & 166 \\
\hline 陕西 & 延安 & 109.50 & 36.60 & 4088 & 154 \\
\hline 新疆 & 莎车 & 77.10 & 38.43 & 3711 & 143 \\
\hline 河北 & 黄骅 & 117.35 & 38.37 & 4692 & 95 \\
\hline 河南 & 国营 & 114.40 & 33.75 & 4071 & 117 \\
\hline 山东 & 莒县 & 118.83 & 35.58 & 3015 & 89 \\
\hline 江苏 & 丰县 & 116.58 & 34.68 & 3729 & 103 \\
\hline 江苏 & 䀒眙 & 118.02 & 33.00 & 3445 & 106 \\
\hline 安徽 & 蒙城 & 116.53 & 33.28 & 4132 & 100 \\
\hline 安徽 & 寿县 & 116.78 & 32.55 & 2345 & 103 \\
\hline 江西 & 龙南 & 114.82 & 24.92 & 3009 & 102 \\
\hline 江西 & 南康 & 114.75 & 25.67 & 2872 & 96 \\
\hline 江西 & 泰和 & 114.92 & 26.80 & 3045 & 95 \\
\hline 湖南 & 怀化 & 107.97 & 27.55 & 2820 & 101 \\
\hline
\end{tabular}

产潜力可能是存在记录误差, 个别年份的记录生产 潜力在 $8000 \mathrm{~kg} / \mathrm{ha}$, 根据查阅到的大豆最高生产潜力 在 $6000 \mathrm{~kg} / \mathrm{ha}$ 左右。然后从剩余观测年份中挑选中值 作为每个站点大豆观测生产潜力。从观测数据来看, 东北地区特别是黑龙江省大豆产量较高, 在 $4000 \mathrm{~kg} / \mathrm{ha}$ 以上, 而南方大部分地区包括江苏、安徽、 江西的大部分观测站点大豆产量较低, 在 $3000 \mathrm{~kg} / \mathrm{ha}$ 左右。生育期长度呈现北长南短的分布规律。在灌 溉方式上, 观测数据中扎兰屯、蒙城、莎车站点有
灌溉纪录, 其他多数站点为雨养种植模式。

\section{2. 研究方法}

AEZ模型同时考虑光、温、水、土、投入水平等 影响生物生产潜力形成的因素及指标。该模型能够 进行土地适宜性以及土地生产潜力评价, 能够得到 农业生态区划图、土地适宜性评价图以及农作物生 产潜力等信息, 为气候变化、土地承载力等研究提 供了依据。根据假定的投入水平、灌溉供给以及管 
理条件, 定义特定作物在气候、土壤、地形以及海 拔因素引起的限制因子, 以此计算得到作物的最大 生产潜力和生产潜力。以土地利用单元 (LUT) 作为 计算潜在生产力的基本单位, 每一种土地利用单元 包含的信息有: 收货系数、最大叶面积指数、最大 光合速率等, 耕作方式和投入需求, 作物残茬和作 物副产品系数。采用的自动匹配算法会依据气候资 源数据和LUT属性数据逐格点尝试所有可能性, 因此 模型能够自动篎选出最优的作物种植品种、种植模 式等, 这使得AEZ模型在区域作物潜在生产力评估中 具有明显优势, 主要步骤是:

(1) 通过气候和土地资源的清查, 建立起研究 区域内逐格点中每个评价单元的气候（温度、降水、 风速、日照时数、相对湿度)、土壤、地形等资源 数据库, 同时定量评估区域内农业气候资源, 包括 积温、湿润指数等;

（2）根据已有资源数据库及其他LUT属性信息, 进行作物与环境匹配, 计算所有作物每个LUT的光温 生产潜力, 以及在土壤、地形、水分、管理水平等

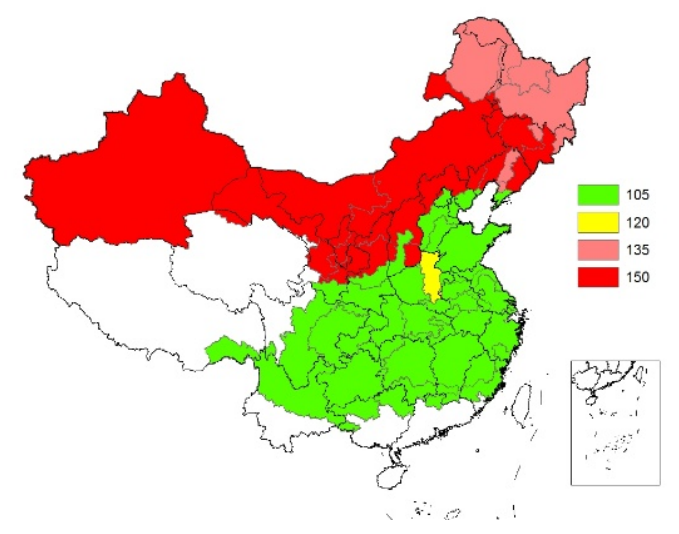

\section{AEZ 模型的验证}

根据大豆观测数据扩充 AEZ 模型的大豆品种 库, 同时结合大豆的观测数据进行对比, 调整大品 种系数。此外根据大豆的观测数据的空间分布, 基 于生态系统类型调整 AEZ 模型的算法, 形成适应于 我国大豆生产的 AEZ 模型版本。以此建立跨尺度模 拟的中国大豆评估模型 China-AEZ ${ }^{[14]}$, 综合评估未 来气候变化影响下我国大豆生产潜力的变化。

\section{(1) AEZ 模型验证}

在 AEZ 模型中, 生育期长度是品种的一个关键 属性, 首先对比原 AEZ 模型得到的生育期分布图与 实际观测值进行比较, 验证原始 AEZ 模型对我国大 豆的模拟能力。在 AEZ 模型中, 生育期作为 LUT 的 一个重要属性, 根据大豆普遍生育期长度, 以 15 天 间隔分成几个代表性生育期。为更明显的比较观测 值与 $\mathrm{AEZ}$ 模型模拟的结果, 将观测站点的品种生育 期长度根据 AEZ 模型的品种库分为 4 类。从图 1 生 育期长度的对比中, 我们可以看到两个主要的不同 点:

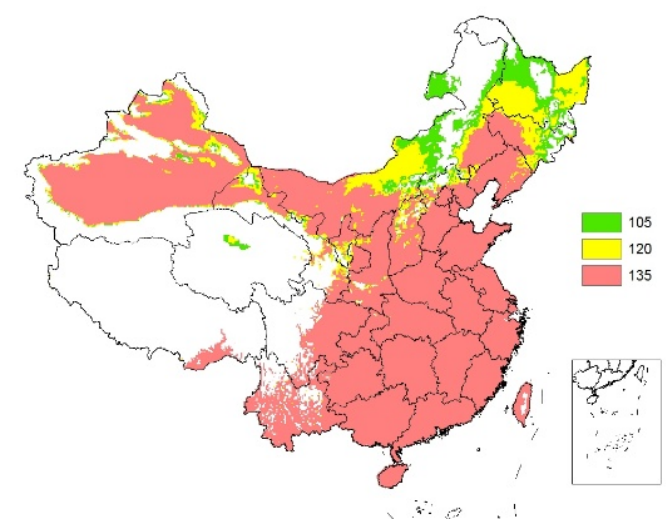

图 1.1990s 下原大豆生育期长度分布实际情况（左）以及 AEZ 模型模拟情况（右）

限制条件下的作物最高生产潜力;

（3）计算由于其它限制因子导致的作物生产潜 力损失, 如干旱、霜冻、作物病虫害等, 并进一步 考虑土壤与地形因素对作物最终潜在生产潜力的影 响。在模拟我国小麦生产潜力中已得到应用 ${ }^{[13]}$ 。但 该模型对农作物生长过程的机理性解释相对而言较 为粗略, 作物生长的微观基础比较薄弱。
1）观测站点中存在 150 天生育期的品种，而在 原始 AEZ 模型的品种库中仅有其他三种类型 (105 天， 120 天，135 天）的生育期长度的品种；2）原 始 AEZ 模型模拟的结果显示在南方、华北大部分地 区选择生育期较长的品种, 而在东北地区则选择了 生育期较短的品种, 呈现为南长北短的趋势, 而实 际观测结果与 AEZ 模型模拟的结果相反, 呈现南短 
北长的趋势, 这主要是因为 $\mathrm{AEZ}$ 模型是采用的自动 算法, 所考虑的因素主要是气候、土壤等客观因素 的影响, 没有考虑区域内复种指数、作物的轮作等 种植者决定的主观因素, 而在我国大部分地区, 大 豆并不是一种主作物, 农民会优先种植小麦、水稻 等收益较大的作物, 从而导致大豆可种植的生育期 就会缩短。

\section{(2) AEZ 模型的调试}

针对原始 AEZ 模型的不足, 通过不断试验模拟, 与观测值进行比较验证。本研究中我们做了两点主 要的改进: 1)在 AEZ 模型的品种库中增加生育期为 150 天的品种, 并根据观测数据补充和改进 AEZ 模 型的其他相关品种参数, 包括收货系数、最大叶面 积指数、积温等, 使之与我国大豆种植生长发育情
况更为吻合。从表 2 中改进的品种参数结果来看, 原有品种收货系数和最大叶面积指数整体上增加, 可增加模拟的生产潜力; 适宜最低积温降低、适宜 最高积温提高, 扩大大豆生长发育对温度的要求范 围，使之适宜于我国南方热量资源丰富的地区。

$\mathrm{AEZ}$ 模型能够根据气候、土壤资源生成八种不 同的耕作系统类型, 通过比较观测值与耕作系统的 关系，发现大豆生育期长度与耕作系统分布之间存 在一定的相关性, 即在单作区内大豆观测生育期长 度较长而在多熟区内大豆生育期较短。基于作物耕 作系统调整 AEZ 模型的自动算法, 使其在一个耕作 系统内根据限制品种的选择, 一种作物耕作系统内 选择特定的品种, 代替原有的完全最优自动算法。

根据表 3 进行品种选择: 其中单作区内大豆生

表 2. AEZ 模型中大豆品种及主要品种参数变化对比（原：原 AEZ 模型; 改：改进后的 AEZ 模型）

\begin{tabular}{|c|c|c|c|c|c|c|c|}
\hline 品种 & $\begin{array}{l}\text { 生育期长 } \\
\text { 度 }\end{array}$ & $\begin{array}{l}\text { 收获 } \\
\text { 系数 }\end{array}$ & $\begin{array}{l}\text { 最大叶面 } \\
\text { 积指数 }\end{array}$ & $\begin{array}{l}\text { 适宜生育期 } \\
\text { 最低积温 }\end{array}$ & $\begin{array}{l}\text { 次适宜生育 } \\
\text { 期最低积温 }\end{array}$ & $\begin{array}{l}\text { 适宜生育期 } \\
\text { 最高积温 }\end{array}$ & $\begin{array}{l}\text { 次适宜生育 } \\
\text { 期最高积温 }\end{array}$ \\
\hline $\begin{array}{c}\text { 温带和亚热带大 } \\
\text { 豆 } 1 \text { (原) }\end{array}$ & 105 & 0.3 & 4.0 & 2200 & 1850 & 2600 & 3150 \\
\hline $\begin{array}{c}\text { 温带和亚热带大 } \\
\text { 豆 1（改） }\end{array}$ & 105 & 0.38 & 4.0 & 2100 & 1850 & 2800 & 3150 \\
\hline $\begin{array}{c}\text { 温带和亚热带大 } \\
\text { 豆 2(原) }\end{array}$ & 120 & 0.35 & 2.5 & 2400 & 2000 & 3000 & 3600 \\
\hline $\begin{array}{c}\text { 温带和亚热带大 } \\
\text { 豆 } 2 \text { (改) }\end{array}$ & 120 & 0.37 & 4.2 & 2300 & 2000 & 3150 & 3500 \\
\hline $\begin{array}{c}\text { 温带和亚热带大 } \\
\text { 豆 } 3 \text { (原) }\end{array}$ & 135 & 0.35 & 3.0 & 2600 & 2150 & 3400 & 4050 \\
\hline $\begin{array}{c}\text { 温带和亚热带大 } \\
\text { 豆 } 3 \text { (改) }\end{array}$ & 135 & 0.36 & 4.5 & 2500 & 2150 & 3450 & 3800 \\
\hline $\begin{array}{c}\text { 温带和亚热带大 } \\
\text { 豆 } 4 \text { (增) }\end{array}$ & 150 & 0.35 & 4.5 & 2700 & 2300 & 3750 & 4100 \\
\hline
\end{tabular}

表 3. AEZ 模型不同耕作系统品种的选择

\begin{tabular}{|l|l|}
\hline 耕作系统类型 & 生育期长度类型的选择 \\
\hline No cropping & \\
\hline Single cropping & \\
\hline Limited cropping & \\
\hline Double cropping 105 天类型中选择最 120 天优生育期 \\
\cline { 1 - 1 } Double cropping with rice & \multirow{2}{*}{ 选择 105 天优生育期 } \\
\hline Double rice cropping & \\
\hline Triple cropping & \\
\hline Triple rice cropping & \\
\hline
\end{tabular}


育期长度的选择不受限制, 模型根据大豆最大生产 潜力选择品种类型, 一般情况下, 在气候资源丰富 的条件下，作物生产潜力与生育期长度之间有一定 的相关性, 优先选择生育期长的品种; 在两熟区, 大豆生育期长度的选择受轮作影响, 限定在 105 天 和 120 天之间选择; 在三熟区, 大豆生育期的选择 更短, 仅限定在 105 天。

\section{3. 结果分析}

\section{1. 大豆生产潜力模拟评估}

我国大豆种植方式以雨养为主, 因此本研究主 要评估雨养条件下大豆生产潜力和适宜区划。基准 气候条件下, AEZ 模拟得到的我国大豆主产区集中 在东北平原、华北平原、长江中下游平原以及四川 盆地等地势较为平坦的地区。模型模拟的结果与我 国大豆主产区有很好的一致性, 历史相关资料表明 我国大豆主产区包括北方春大豆（包括东北地区、 黄土高原、西北地区) 、黄淮海夏大豆 (包括晋冀 中部、黄淮海流域)、长江流域春夏大豆（包括长 江流域、云贵高原）、东南春夏秋大豆（浙江、福 建、江西、台湾、湖南、广东、广西大部）以及华 南四季大豆 (广东、广西、云南和福建南部)。图 2 模拟 1990s 大豆生产潜力分布: 其中大豆生产潜力最 大的区域位于东北省境内, 很多区域在 $4000 \mathrm{~kg} / \mathrm{ha}$ 以 上, 这与该区属于一熟制, 大豆生育期较长有关, 模拟的大豆生产潜力与观测的大豆生产潜力较为相 近, 特别是黑龙江省的德都、巴彦站点附近区域大 豆生产潜力处于极高水平; 华北平原的山东、河北、 河南部分区域大豆生产潜力接近 $4000 \mathrm{~kg} / \mathrm{ha}$, 而实际 观测中河北的黄骅、河南的国营大豆生产潜力也高 于 $4000 \mathrm{~kg} / \mathrm{ha}$; 虽然南方水热资源丰富, 但改进后的 AEZ 模型对品种的选择受区域内熟制分布的限制, 考虑多熟制轮作的影响, 因而不能充分利用气候资 源, 大豆生产潜力不如东北地区高, 在 $3000 \mathrm{~kg} / \mathrm{ha}$ 左 右, 与观测的站点 (安徽的蒙城、寿县, 江西的龙 南、南康、泰和以及湖北的怀化) 的大豆生产潜力 相近。以上结果表明改进后的 AEZ 模型模拟得到的 大豆生产潜力空间分布能够较好的反映我国观测种 植大豆生产潜力情况, AEZ 对我国大豆生产具有较
好的模拟能力。

图 3 结果表明: 到 2050s 未来气候变化下, 在使 用最优播期和限制性的适宜品种的情况下, 总体上 气候变化对大豆生产的影响呈现北增南减的趋势, 东北以及华北部分地区受全球变暖的影响, 冻害、 大雪等低温灾害发生频率减少, 有相当一部分地区 大豆增产 $500 \mathrm{~kg} / \mathrm{ha}$ 以上, 且黑龙江、内蒙古以及河 北省部分地区增产幅度在 $1000 \mathrm{~kg} / \mathrm{ha}$, 仅有黑龙江西 部以及辽宁中部地区有小幅减产, 均少于 $250 \mathrm{~kg} / \mathrm{ha}$; 华北、华中南部以及南方大部分地区呈现减产趋势, 主要原因是华北地区处于熟制交界地带, 气候变暖 下该区熟制增加, 缩短了大豆适宜生育期长度的选 择, 导致大豆减产; 而华中南部以及南方地区可能 是由于该区热量资源本身较为丰富, 加上气候变暖, 高温热浪的灾害增加, 不利于作物生长, 导致大豆 生育期缩短, 从而导致大豆减产, 但是大部分地区 减产幅度较小, 均低于 $500 \mathrm{~kg} / \mathrm{ha}$; 山东、河北、河 南以及安徽、江苏北部等处于熟制过度地带, 大豆 生育期长度变化较大, 大豆减产趋势较为明显, 高 于 $500 \mathrm{~kg} / \mathrm{ha}$ 。

\section{2. 大豆适应种植区域分析}

表 4 结果显示, 气候变化影响下, 我国大豆适 宜种植面积增加 3589 千公顷, 总产量增加 7123 千 吨, 但是大豆单位面积产量减少 $55 \mathrm{~kg} / \mathrm{ha}$ 。

AEZ 模型将我国分为华北、东北、华东、华中、 东南、西南、西藏高原、西北八个区域统计分析, 其中华北地区包括北京市、天津市、河北省、山西 省、山东省、河南省和湖北省, 东北地区包括辽宁 省、吉林省和黑龙江省, 华东地区包括上海市、江 苏省、浙江省和安徽省, 华中地区包括江西省和湖 南省, 东南地区包括福建省、广东省、广西省和海 南省, 西南地区包括重庆市、四川省、贵州省和云 南省, 高原地区包括西藏自治区和青海省, 西北地 区包括新疆自治区、内蒙古自治区、陕西省、甘肃 省和宁夏自治区。

在使用了最优播期和最优限制性品种选择计算 得到的大豆生产潜力中, 表 5 统计结果显示, 雨养 条件下, 大豆主产区集中在华北、东北、西南和西 北地区，1990s 以上地区大豆产量占大豆总产的 


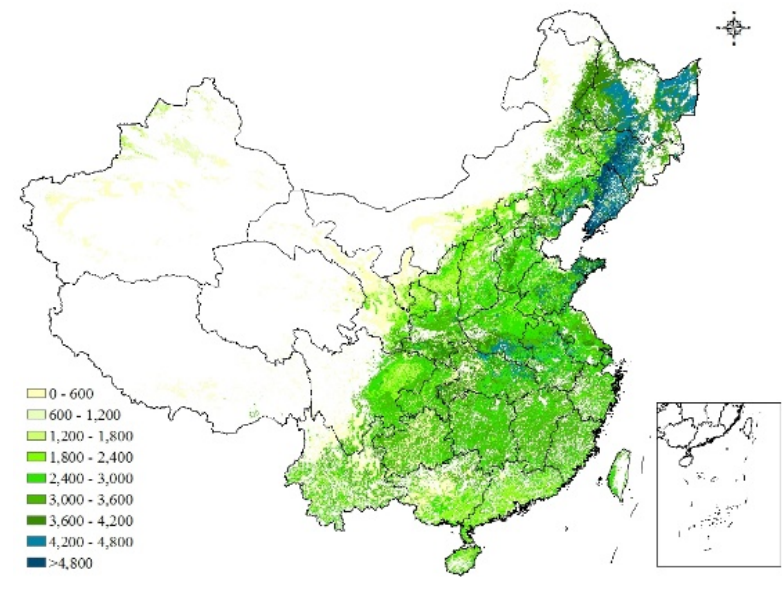

图 2.1990s 大豆生产潜力模拟

表 4. 大豆生产总体统计结果

\begin{tabular}{|l|l|l|l|}
\hline 时间 & 适宜面积 (千公顷) & 总产 (千吨) & 单产 (kg/ha) \\
\hline $1990 \mathrm{~s}$ & 58332 & 171616 & 2942 \\
\hline $2050 \mathrm{~s}$ & 61921 & 178739 & 2887 \\
\hline
\end{tabular}

表 5. 大豆生产分区域统计结果

\begin{tabular}{|c|c|c|c|c|c|c|}
\hline \multirow{2}{*}{ 区域 } & \multicolumn{2}{|c|}{ 适宜面积 (千公顷 } & \multicolumn{2}{|c|}{ 总产（千吨） } & \multicolumn{2}{|c|}{ 单产 (kg/ha) } \\
\hline & $1990 \mathrm{~s}$ & $2050 \mathrm{~s}$ & $1990 \mathrm{~s}$ & $2050 \mathrm{~s}$ & $1990 \mathrm{~s}$ & $2050 \mathrm{~s}$ \\
\hline 华北 & 12645 & 13029 & 35337 & 33984 & 3105 & 2898 \\
\hline 东北 & 15461 & 15538 & 57274 & 63526 & 4116 & 4543 \\
\hline 华东 & 4250 & 4271 & 11981 & 10335 & 3133 & 2689 \\
\hline 华中 & 2253 & 2253 & 6146 & 5556 & 3031 & 2739 \\
\hline 华南 & 4074 & 4138 & 9628 & 8615 & 2626 & 2313 \\
\hline 西南 & 11253 & 12260 & 29646 & 28687 & 2927 & 2600 \\
\hline $\begin{array}{l}\text { 青藏高 } \\
\text { 原 }\end{array}$ & 40 & 125 & 93 & 278 & 2561 & 2472 \\
\hline 西北 & 8356 & 10307 & 21511 & 27758 & 2860 & 2993 \\
\hline
\end{tabular}

$71.2 \%$ 。1990s 下，华北和东北地区是大豆总生产潜 力最高的地区, 占总生产潜力的 $52.3 \%$, 气候变化影 响下大豆总产有小幅增加, 为 7123 千吨, 除西北和 东北两个地区, 其他地区大豆总生产潜力均有减少。 适宜面积增加 3589 千公顷, 增加明显的地区为华北、 西南和西北地区, 该区位于高纬度地区和山区, 主 要驱动因素可能是气候变暖影响下, 该区热量资源 增加。从平均生产潜力来看, 1990s 下大豆均产最高 的地区位于东北, 平均生产潜力高于 $4000 \mathrm{~kg} / \mathrm{ha}$, 其 他地区在 $3000 \mathrm{~kg} / \mathrm{ha}$ 左右, 气候变化下大豆总体平均 生产潜力降低 $55 \mathrm{~kg} / \mathrm{ha}$, 除东北和西北地区大豆均产

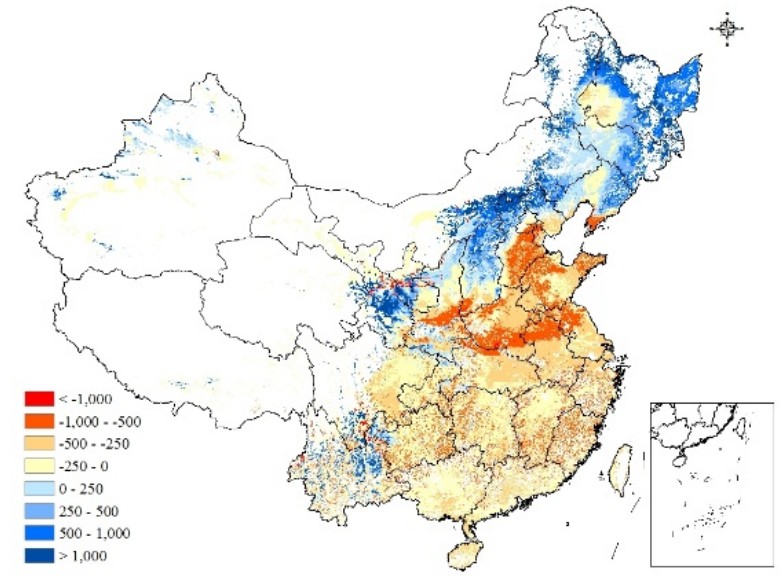

图 3. 2050s 大豆生产潜力的变化 $(\mathrm{kg} / \mathrm{ha})$.

有增加外, 其他地区大豆均有小幅减产。

\section{4. 结论及讨论}

本研究基于大豆观测值对 AEZ 模型的大豆品种 库参数进行有效的扩充和改进, 改进后的 AEZ 模型 能够更为准确地模拟我国大豆生产潜力及种植区 划。未来气候变化下, 总体来看气候变化有利于东 北、西北以及华北北部地区大豆生产，但不利于华 北大部、南方大部分大豆生产。统计结果显示大豆 总产和总适宜

面积增加, 平均生产潜力减少。区域上来看, 气候 变化下带来的热量资源增加有利于东北及西北地区 大豆生产，华北以及南方大部分地区均有小幅减产。

虽然本研究中 AEZ 模型对大豆遗传参数进行了 调整改进，但对适宜播期的模拟仍然是采用最优播 期，并未考虑多熟制内其他主作物对大豆种植播期 的限制, 今后还需进一步探讨多熟制内的作物轮作 模式, 以期得到更为准确的结果。

\section{参考文献}

[1]Masuda T, Goldsmith P D. World Soybean Demand: An Elasticity Analysis and Long-Term Projections. National Soybean Research Laboratory University of Illinois at Urbana-Champaign, Urbana, Illinois, 2009.

[2]Masuda T, Goldsmith P D. World soybean production: area harvested, yield, and long-term projections. International Food and Agribusiness Management Review, 2009, 12(4): 143-162. 
[3]李秀娟, 刘喜元, 李晓伟, 等.2009年呼伦贝尔市岭东地 区大豆生产的气象条件分析. 现代农业科技，2010， (20):297, 299.

[4]DING Y H, REN G Y, ZHAO Z, et al. Detection, causes and projection of climate change over China: An overview of recent progress. Advances in Atmospheric Sciences, 2007, 24(6):954-971.

[5]任国玉, 封国林, 严中伟. 中国极端气候变化观测研究 回顾与展望. 气候与环境研究, 2010, 15(4):337-353.

[6]王会军, 孙建奇, 祝亚丽. 中国极端气候及东亚地区能 量和水分循环研究的若干近期进展. 自然杂志, 2012, 34(1):10-17.

[7]左德鹏, 徐宗学, 李景玉, 等. 气候变化情景下渭河流 域潜在蒸散量时空变化特征。水科学进展, 2011, 22(4):455-461.

[8]Gamble D W, Campbell D, Allen T L, et al. Climate Change, Drought, and Jamaican Agriculture: Local Knowledge and the Climate Record. Annals of the Association of American Geographers, 2010, 100(4):880-893.

[9]王丽, 霍治国, 张蕾, 等. 气候变化对中国农作物病害 发生的影响[J]. 生态学杂志, 2012, 31(7):1673-1684.
[10]Chen H, Zhang H, Xue C. Chinese Extreme Climate Events and Agricultural Meteorological Services. Challenges and Opportunities in Agrometeorology. Springer Berlin Heidelberg, 2011:435-459.

[11]田展, 丁秋荣, 梁卓然, 等. 气候变化对中国油料作物 的影响研究进展. 中国农学通报, 2014, (15):1-6.

[12]施小英, 徐祥德, 徐影. 中国 600 个站气温和 IPCC 模 式产品气温的比较. 气象, 2005, 31(7):49-53.

[13]田展,钟洪麟, 施润和, 等. Estimating potential yield of wheat production in China based on cross-scale data-model fusion. Frontiers of Earth Science, 2012, 6(4): 364-372.

[14]Fan D, Ding Q, Tian Z, et al. Simulating the adaptive measures of soybean production to climate change in China: Based on cross-scale model coupling. Emerging Economies, Risk and Development, and Intelligent Technology: Proceedings of the 5th International Conference on Risk Analysis and Crisis Response, June 1-3, 2015, Tangier, Morocco. CRC Press, 2015: 143. 